\title{
Interchanged Precordial Electrodes by ECG Finding
}

National Cancer Institute

\section{Source}

National Cancer Institute. Interchanged Precordial Electrodes by ECG Finding. NCI

Thesaurus. Code C114152.

An electrocardiographic recording in which two or more of the precordial electrodes are switched resulting in improper representation of the affected leads. (CDISC) 